\title{
Construction and Application of Evaluation Index System of Circular Economy in Sichuan Province
}

\author{
Jinyang Liu ${ }^{1, a,{ }^{*}}$, Yamin Wang ${ }^{2, b}$, Sheng Zhu ${ }^{1, \mathrm{c}}$ and Lijun Ran ${ }^{1, \mathrm{~d}}$ \\ ${ }^{1}$ School of Statistics, Chengdu University of Information Technology, Sichuan Province, China \\ ${ }^{2}$ Sichuan Institute of Statistics, Chengdu, Sichuan Province, China \\ alista@cuit.edu.cn, ${ }^{\text {b5 } 51180210 @ q q . c o m, ~}{ }^{\mathrm{c}} \mathrm{tj} x @$ @cuit.edu.cn, ${ }^{\mathrm{d}}$ ran_ljun@126.com \\ ${ }^{*}$ Corresponding author
}

Keywords: Circular economy, Evaluation index system, Comprehensive evaluation.

\begin{abstract}
The development of circular economy plays an important role in alleviating resource constraints, protecting the ecological environment, adjusting industrial structure, promoting economic growth, stabilizing employment expansion, promoting green transformation and development, and building ecological civilization. This paper constructs a set of objective, scientific and comprehensive evaluation index system of circular economy, and measures the development of circular economy in Sichuan Province. On this basis, it puts forward suggestions for promoting the development of circular economy in Sichuan Province.
\end{abstract}

\section{Introduction}

\subsection{Proposal of circular economy}

The idea of circular economy originated from the "spaceship theory" proposed by American economist Kenneth Ewert Boulding in 1960s. He advocates the establishment of a "circular economy" that does not deplete resources, does not cause environmental and ecological pollution, and can recycle various resources, instead of the "single-program economy" of the past. Circular economy mainly refers to the transformation of the traditional linear growth economy depending on resource consumption into the economy depending on ecological resource circulation in the whole process of resource input, enterprise production, product consumption and its abandonment in the large-scale system of human, natural resources and science and technology.

In 1999, China introduced the idea of circular economy. Since 2000, the National Development and Reform Commission and the State Environmental Protection Administration have vigorously promoted the development model of circular economy nationwide. A lot of work has been done from ideological propaganda, policy guidance, and technical support. The 22nd document issued by the State Council in July 2005, "Several Opinions of the State Council on Accelerating the Development of Circular Economy" is a sign that China's circular economy work has entered from the initial stage. A comprehensive pilot phase.

\subsection{Connotation of circular economy}

Circular economy is the abbreviation of material closed-loop flow economy. It is a closed-loop circulation economic development model consisting of "resources-products-renewable resources". Circular economy refers to the rational use of existing resources in the economic activities of human society by using the laws of ecology. By optimizing the cycle and energy flow of material in economic activities, reducing the input and output of resources and pollution, the waste in the production process can be reduced, resourced and harmless, So as to realize the cycle and sustainable development of economic system and ecosystem. Circular economy is a kind of economic growth mode with the core of efficient utilization and recycling of resources and the basic characteristics of 
low consumption, low emission and high efficiency, which conforms to the sustainable development. [1].

\subsection{Principle of circular economy}

The circular economy should follow the principle of "reduction, reuse, recycling" (ie 3R). The principle of reduction is an input method, which aims to reduce the quality of goods entering the production and consumption processes; The reuse principle is a process approach, with the aim of prolonging the time intensity of products and services; the principle of recycling belongs to the output method, which reduces the final throughput by turning waste into resources again. The importance of the 3R principle of circular economy is not juxtaposed, so the weights of each criterion level in the evaluation system of circular economy are also different. The determination of the weights of criterion level should be based on the priority development order of "reduction-reuse-recycling" principle of circular economy[2].

\section{The construction of evaluation index system}

\subsection{Construction principle}

\subsubsection{Scientific and guiding}

The selection of circular economy evaluation indicators is based on the science of full understanding and systematic research. It can reflect the main characteristics of circular economy. The data source should be accurate and the processing method should be scientific. The constructed index system can objectively and comprehensively reflect the contents of resource output, resource consumption, pollution reduction and recycling, and follow the 3R principle of circular economy, have certain guiding significance and practical value for the development of circular economy in the province.

\subsubsection{Comprehensiveness and representativeness}

The setting of the indicator system should reflect all aspects of the development of circular economy in Sichuan as comprehensively as possible, covering the aspects of reduction, reuse, recycling, and economic and social benefits. The selected indicators should be representative and typical, avoiding the selection of similar and repeated indicators. The regional circular economy evaluation has regional characteristics. Therefore, the selected indicators must be based on the reality of Sichuan, highlight the characteristics of Sichuan.

\subsubsection{Systematic and hierarchical}

The circular economy evaluation index system is a complex large system consisting of several subsystems such as resources, environment and economy. These subsystems must not only objectively reflect all aspects of the development of circular economy, but also maintain mutual independence and avoid overlapping. At the same time, it should be divided into the target layer, the criterion layer and the index layer according to the structure of the system. The target layer is the purpose of comprehensive evaluation of circular economy. The criterion layer is the inductive classification of many evaluation indicators. There must be obvious boundaries between the target layer, the criterion layer and the indicator layer. The three levels form a comprehensive evaluation index system of circular economy with clear structure, clear hierarchy and organic connection from large to small.

\subsubsection{Comparability and operability}

In the selection of evaluation indicators, the first is to select the indicators that are more significant with the development of the circular economy to ensure the longitudinal comparability of the same indicators in time; the second is to link with the national circular economy evaluation index system as much as possible. The statistical caliber and scope of the indicators are generally consistent to ensure the horizontal comparability of the indicators in the spatial scope. In addition, the setting of the indicator system should be as simple and straightforward as possible, avoid too cumbersome, fully consider the reliability and difficulty of data acquisition, make full use of existing statistical data and 
indicators that are easy to collect statistical data, so that the indicator system has strong abilities. Operational.

\subsection{Basic framework}

The target layer represents the comprehensive index of circular economy development, that is, the overall status and level of circular economy development, which is reflected by the criteria layer; the criteria layer includes five subsystems, namely resource output system, resource consumption system, recycling system, waste discharge system and economic development system, which is expressed by the indicator layer; the indicator layer consists of 19 basic indicators, corresponding to the five subsystems of the criterion layer.

Table 1. Comprehensive evaluation index system of circular economy

\begin{tabular}{|c|c|c|c|c|}
\hline Target layer & Criteria layer & Indicator layer & Nature & Weights \\
\hline \multirow{19}{*}{$\begin{array}{l}\text { Comprehensiv } \\
\text { e development } \\
\text { index of } \\
\text { circular } \\
\text { economy }\end{array}$} & \multirow{2}{*}{$\begin{array}{l}\text { Resource output } \\
\text { system }\end{array}$} & Resource output rate & Positive & 10 \\
\hline & & Energy output rate & Positive & 9 \\
\hline & \multirow{5}{*}{$\begin{array}{c}\text { Resource } \\
\text { consumption system }\end{array}$} & Unit GDP energy consumption & Reverse & 9 \\
\hline & & Unit industrial added value energy consumption & Reverse & 7 \\
\hline & & Unit GDP water withdrawal & Reverse & 6 \\
\hline & & Unit industrial added value water consumption & Reverse & 6 \\
\hline & & Effective use of agricultural irrigation water & Positive & 6 \\
\hline & \multirow{5}{*}{ Recycling system } & $\begin{array}{l}\text { Industrial energy recycling rate above designated } \\
\text { size }\end{array}$ & Positive & 6 \\
\hline & & Reuse of industrial water above the scale & Positive & 6 \\
\hline & & $\begin{array}{l}\text { Comprehensive utilization rate of industrial solid } \\
\text { waste }\end{array}$ & Positive & 5 \\
\hline & & Urban sewage treatment rate & Positive & 5 \\
\hline & & $\begin{array}{l}\text { Harmless treatment rate of urban domestic } \\
\text { garbage }\end{array}$ & Positive & 6 \\
\hline & \multirow{4}{*}{$\begin{array}{l}\text { Waste discharge } \\
\text { system }\end{array}$} & Industrial solid waste discharge & Reverse & 4 \\
\hline & & Unit GDP wastewater discharge & Reverse & 4 \\
\hline & & Major pollutant emissions & Reverse & 5 \\
\hline & & Municipal solid waste removal volume & Reverse & 6 \\
\hline & \multirow{3}{*}{$\begin{array}{c}\text { Economic } \\
\text { development system }\end{array}$} & $\begin{array}{l}\text { The added value of the tertiary industry accounts } \\
\text { for the proportion of GDP }\end{array}$ & Positive & 10 \\
\hline & & $\begin{array}{l}\text { Environmental pollution control investment } \\
\text { accounts for the proportion of GDP }\end{array}$ & Positive & 9 \\
\hline & & $\begin{array}{l}\text { The total output value of high energy-consuming } \\
\text { industries accounts for the proportion of total } \\
\text { industrial output value of all scales }\end{array}$ & Reverse & 9 \\
\hline
\end{tabular}

\subsection{Comprehensive evaluation method}

\subsubsection{Determination of weight}

Index weights are used to reflect the size of a single indicator in the comprehensive evaluation system. The rationality and scientificity of the weight determination will directly affect the evaluation results. This paper adopts the comprehensive assignment method combining subjective assignment method and objective assignment method. Firstly, a set of weights is measured by objective assignment method, then the subjective assignment method is used to adjust and balance the calculation results, and the advantages and disadvantages of the two methods are combined to make the setting of weights more scientific and reasonable. The objective assignment method in this paper adopts the authoritative entropy method. The subjective assignment method adopts the more widely used analytic hierarchy process and expert evaluation method, and the final index weight is obtained through comprehensive adjustment.

In the process of weight setting, due to the lack of data on the three indicators of resource output rate, unit GDP water intake and water consumption per unit of industrial added value, the evaluation finally adopted the remaining 16 effective indicators. Secondly, due to the discharge of industrial 
solid waste varies greatly, the indicator is smoothed when measuring. The results of the empowerment are shown in Table 1.

\subsubsection{Index calculation}

The calculation of the circular economy development index uses the commonly used linear weighting method. Taking the 2014 index value as the standard value, that is, the 2014 circular economy development index is the base value of 100 , and the dimension data of the indicator data is realized by the standard value, the positive indicator is dimensionless to

$$
y_{i j}=\left(\frac{z_{i j}}{z_{i j b}}\right) \times 100
$$

, the negative indicator is dimensionless to

$$
y_{i j}=\left(\frac{z_{i j b}}{z_{i j}}\right) \times 100
$$

, where $y_{i j}$ is the dimensionless value of $z_{i j}, z_{i j}$ is the actual value, and $z_{i j b}$ is the standard value.

Through the weighting of individual indicators, five classification indicator indexes are obtained, and the comprehensive index of circular economy can be obtained by weighting the index of classification index again. The calculation formula is

$$
h=\sum w_{i} f_{i}
$$

, where $w_{i}$ is the weight of the classification index, and $f_{i}$ is Classification indicator index.

\section{Comprehensive evaluation of circular economy development}

\subsection{The overall level of circular economy development is high, and effectiveness is obvious.}

In 2017, the comprehensive development index of Sichuan's circular economy was 117.4 (based on 2014), an increase of 17.4 points over 2014, with an average annual increase of 5.8 points. The national circular economy development index increased by an average of 4 points per year, and the average growth rate of the Sichuan circular economy development index was higher than the national 1.8 points. Among them, the faster growth is the resource consumption index, the economic development index and the resource output index, which respectively boost the comprehensive index of circular economy development by 5.1, 4.7 and 2.0 percentage points. The development of recycling index and waste discharge index is relatively slow, and the comprehensive index of circular economy development is promoted by 3.3 percentage points and 2.3 percentage points respectively. The development of circular economy in Sichuan Province is generally faster, with obvious results and great development potential.

\subsection{Resource output is gradually increasing, and resource consumption is declining}

In 2017, Sichuan's resource output index was 120.2, an increase of 20.2 points over 2014, with an average annual increase of 6.7 points. In 2017, the resource consumption index of Sichuan Province was 120.4, which was 20.4 points higher than that of 2014, with an average annual increase of 6.8 points. Compared with 2014, two of the three resource consumption indicators showed a significant decline in the reverse index, and one positive indicator continued to increase.

\subsection{The level of resource recycling has steadily improved, but progress has been slow.}

In 2017, the recycling index of Sichuan Province was 111.0, which was 11.0 points higher than that of 2014, with an average increase of 3.7 points per year, which is the smallest increase among the five classification indicators. Compared with 2014, 4 of the 5 recycling indicators have improved, and 1 has declined. The comprehensive utilization rate of industrial solid waste dropped significantly, from 
47.2\% in 2014 to 42.9\% in 2017, which lowered the recycling index. The level of resource recycling in Sichuan Province needs to be further improved.

\subsection{Waste discharge continues to decrease, but the results are not significant enough}

In 2017, Sichuan's waste discharge index was 111.5, an increase of 11.5 points over 2014, an average annual increase of 3.8 points, and a small increase in the five classification indicators. Compared with 2014, the discharge of major pollutants and the discharge of wastewater per unit of GDP in the four waste discharge indicators are the most obvious. The amount of municipal solid waste removal is not falling, and the discharge of industrial solid waste is highly volatile. The effectiveness of waste reduction in Sichuan Province needs to be further improved, and the public awareness of environmental protection needs to be strengthened.

\subsection{The level of economic development is relatively high and the improvement is obvious}

In 2017, the economic development index of Sichuan Province was 131.1, which was 31.1 points higher than that of 2014, with an average annual increase of 10.4 points, which was the biggest increase among the five classification indicators. Compared with 2014, the two positive indicators of economic development in 2017 have all increased significantly, and one negative indicator has decreased significantly. In recent years, the economic development level of Sichuan Province has been continuously improved, the industrial structure has been gradually optimized, and environmental governance investment has increased year by year, and the pulling effect on the development of circular economy in the province has been continuously enhanced.

\section{Conclusion and suggestion}

According to the basic characteristics of circular economy, referring to the national evaluation index system of circular economy, combining with the reality of Sichuan Province, and based on the existing data, this paper establishes an objective and scientific evaluation index system of circular economy in Sichuan Province, which can be used to quantitatively judge the development of circular economy in Sichuan Province and promote circular economy. Judging from the current development status and evaluation results of circular economy in Sichuan Province, the development of circular economy in Sichuan Province is still in the promotion stage, and it is necessary to take active policy measures to continuously promote the rapid and healthy development of circular economy.

\subsection{Strengthen supervision and management, increase energy conservation and emission reduction}

Sichuan is in an accelerated period of industrialization and urbanization and it has strong dependence on resources. Improving resource utilization efficiency, reducing resource consumption and waste discharge are still important measures to develop circular economy in Sichuan. First, actively promote key projects for resource conservation; second, vigorously promote key projects for emission reduction and pollution prevention; third, increase supervision and management.

\subsection{Strengthen technical support and improve resource recycling rate}

Resource recycling is an important part of the development of circular economy. Improving the efficiency of resource recycling is of great significance for the development of circular economy in Sichuan Province. First, accelerate the research and development and promotion of resource recycling technology, improve the comprehensive utilization level of resources in Sichuan Province; second, accelerate the construction of "urban minerals" demonstration base; third, we should speed up the cultivation of a number of automobile parts, construction machinery, mining machinery and other remanufacturing demonstration enterprises, and promote the standardization and industrialization of remanufacturing. 


\subsection{Adjust industrial structure and optimize industrial layout}

First, accelerate the development of strategic emerging industries and service industries, and gradually increase the proportion of tertiary industry in regional GDP; second, actively resolve excess capacity and eliminate backward production capacity, vigorously reduce energy consumption, and strive to improve economic efficiency; third, we should pay attention to rational distribution, avoid industrial isomorphism, base on market demand and long-term development, and grasp the relationship between traditional industries and emerging industries[3].

\subsection{Increase investment in science and technology and deepen innovation drive}

The first is to establish a circular economy science and technology innovation system that combines government leadership, enterprise subject, Government-Bussiness-University-Research and social participation to provide strong support for the development of circular economy. Second, increase investment in science and technology, support the commonality of circular economy and key technology development, and accelerate the construction of the enterprise independent innovation system; the third is to speed up the popularization and application of new technologies, new technologies, new materials, new products and new equipment in circular economy.

\subsection{Strengthen system construction and strengthen policy support}

The development of circular economy is a systematic project integrating technology, economy and society. It requires policies, laws, regulations and systems as guarantees. The first is to improve the legal system and management system; the second is to increase financial support and improve financial support policies; third, implement tax incentives and improve price policies.

\subsection{Deepen publicity and education to raise public awareness}

Taking the promotion and education of circular economy as a long-term work, making full use of channels such as television, radio and internet to carry out circular economy education and knowledge popularization activities in Sichuan Province, vigorously carry out mass circular economy rationalization proposals, technological innovation, and strengthen the public's perceptual cognition of developing circular economy, establish the concept of circular economy development, and fully mobilize the masses to actively participate in the development and construction of circular economy.

\section{References}

[1] Yunyan Li, Chenxi Yin, Establish a scientific evaluation system to promote the development of circular economy , Environmental protection, vol.17, pp. 21-26, 2016.

[2] Maozhen Wang, Zhijun Feng, Research on Evaluation Index System of Circular Economy Innovation, China Population, Resources and Environment, vol.4, pp. 163-166, 2012.

[3] Di Wu, The Realistic Path of Developing Circular Economy in China, Taxation and Economy, vol.5, pp. 23-26, 2016. 